Raizes,

Ano XVIII

$N^{\circ} 19$

maio/99
Sergio Ricardo Ribeiro de Lima

Professor Assistente do Departamento de Economia da Universidade Estadual de Santa Cruz (UESC), Ilhéus, Bahia. Mestre em Economia, Universidade Federal da Paraíba. Email:srlima@mailbr.com.br

\title{
Modernização e crise do setor sucro-alcooleiro da Paraíba ${ }^{1}$
}

\section{Introdução}

O complexo canavieiro-sucroalcooleiro brasileiro vive uma de suas piores crises desde o início do processo de modernização e crescimento acelerado nos anos 70 e primeira metade dos anos 80 , impulsionado pelo Proálcool. Tal modernização foi possível graças aos créditos e subsídios governamentais oriundos do Proálcool, conforme evidenciado por ARAGÃO (1993). A partir de 1986, com a queda dos preços internacionais do petróleo e com a crise fiscal do Estado brasileiro, o governo começa a rever sua política de fomento ao setor. A contenção do crédito e o controle dos preços do açúcar e do álcool, resultou na defasagem dos preços destes produtos e na inadimplência dos usineiros junto aos bancos oficiais e no conseqüente fechamento de várias unidades industriais na Paraíba. A crise repercutiu também na frástica redução da fabricação de carros movidos a álcool, reforçando ainda mais a crise do setor pela diminuição da demanda pelo álcool automotivo.

Alguns estudos apontam uma série de fatores como responsável pelo baixo nível de eficiência e competitividade do complexo canavieiro-sucro-alcooleiro nordestino. SZMRECSÁNYI (1979) e SALES (1982) levantam aspectos de ordem
Paulo Ortiz Rocha de Aragão

Professor Titular de Economia do Departamento de Economia e Finanças e do Mestrado em Economia Rural e Regional, Campus II da Universidade Federal da Paraíba. Ph. D. em Sociologia, Universidade de Maryland, College Park, U.S.A.

Email:paragao@openline.com.br. estrutural, como a não capitalização do setor, ao contrário do que ocorreu em São Paulo; a distância dos principais centros de consumo, o desenvolvimento no Centro-Sul da industrialização e de uma indústria de bens de capital voltada para o setor, assim como do setor de serviços. MOREIRA \& MOREIRA (1992) citam o modelo de produção tradicional dominante e dominado pelas oligarquias açucareiras. Em estudo mais recente, NOVAES (1993) e BARROS (1996) partilham da idéia de que o atraso tecnológico da agricultura e o baixo desenvolvimento de pesquisas continuam sendo as principais razões da permanência da baixa produtividade do complexo canavieiro-sucro-alcooleiro, cha-

- ${ }^{1}$ Este texto se baseia em pesquisa que serviu de base à Dissertação de Mestrado "Moderniza-

- ção e Crise do Setor Sucro-Alcooleiro da Paraíba” defendida junto ao Curso de Mestrado em

- Economia da UFPB, Campus II - Campina Grande, em 27/11/97.

- Somos gratos aos gerentes industriais e agrícolas das empresas visitadas que pacientemente

- respondeream aos questionários e às entrevistas e forneceram dados importantes sobre suas

- empresas, tornando possível a realização desta pesquisa. 
mando a atenção para os reduzidos teores de sacarose da cana que resultam, em parte, num baixo rendimento industrial.

No caso da Paraíba, a crise econômica desse complexo é ainda mais grave, face a grande dependência do estado dessa atividade econômica e, mais ainda, por ser esta a sua principal atividade agro-industrial, em termos de valor da produção, do número de empregos criados e um dos pilares de sustentação da economia local. Enfim, por se tratar de um estado com fraca atividade econômica, tanto em nível regional como nacional, é da maior importância para a sua economia o bom desempenho do complexo canavieiro. Porém, o que se tem assistido a partir de meados dos anos 80 e no decorrer dos anos 90, é o endividamento, a crise econômica e o declínio da quase totalidade das usinas. Esta crise se evidencia pela paralisação, fechamento, fusão ou venda de algumas usinas, enquanto as que se encontram funcionando estão operando em situação de debilidade financeira. As destilarias, embora também tenham contraído dívidas, porém em grau menor, mantêm-se modernizadas e em processo contínuo de modernização tecnológica. Esta crise econômica tem tido reflexos macroeconômicos para a economia do estado e impactos sociais importantes.

A modernização do complexo canavieiro-sucro-alcooleiro tinha como objetivo básico atacar as causas fundamentais da ineficiência do setor tanto a nível industrial como agrícola. Para tanto, promo- veram-se inovações tecnológicas das instalações e equipamentos para a indústria e agricultura, pesquisa e desenvolvimento de novas variedades de cana mais produtivas, introdução do pagamento da cana pelo teor de sacarose (PCTS), como forma de incentivar o cultivo de variedades mais produtivas, principalmente por parte de fornecedores. A questão que se levanta é a das causas da permanência dos baixos índices de produtividade e competitividade do setor na Paraíba e da crise em que se encontra.

O objetivo deste estudo é verificar quais os fatores responsáveis pela permanência da baixa produtividade e competitividade do complexo canavieiro-sucro-alcooleiro da Paraíba e pela crise em que se encontra, apesar do setor ter passado recentemente por um processo de modernização.

\section{Evolução do complexo canaviei- ro-sucro-alcooleiro na Paraíba, 1970-97}

O setor canavieiro-sucro-alcooleiro assume importância na Paraíba a partir da instituição do Programa Nacional do Álcool (Proálcool), na segunda metade dos anos 70, através da política de estímulos e incentivos financeiros governamentais à implantação e modernização de destilarias anexas às usinas existentes e na década de 80 , com a implantação de destilarias autônomas. Nestas duas décadas, a indústria sucroalcooleira paraibana teve seu parque modernizado, adquirindo equipamentos e instalações modernas, em sua maior parte das indústrias de bens de capital de origem nacional, localizadas no Centro-Sul, a exemplo do grupo DEDINI, que congrega vários ramos industriais de produção de equipamentos e instalação para usinas e destilarias.

Na primeira fase do Proálcool foram implantadas destilarias anexas às usinas Santa Helena, Santa Maria, Santa Rita, São João e Santana. Em 1979 havia na Paraíba 7 usinas e 3 destilarias autônomas. $\mathrm{Na}$ safra 1989/90 continuava-se com 7 usinas, 5 com destilarias anexas e o número de destilarias autônomas havia crescido para 9. Já em 1997 o número de usinas tinha se reduzido para 3 (2 com destilarias anexas) e o de destilarias autônomas para 7 (Quadro 2).

Com o segundo choque do Petróleo em 1979, os incentivos ao Proálcool foram multiplicados, repercutindo na aprovação de projetos de implantação de destilarias no país. $\mathrm{Na}$ década de 80 , o setor canavieiro-sucro-alcooleiro recebe um grande impulso na Paraíba. No final dos anos 70, até a segunda metade da década de 80, são implantadas 9 destilarias autônomas; tem-se, então, uma difusão da cultura canavieira não apenas nas áreas tradicionais a esta cultura como também e principalmente, sobre a área de tabuleiros costeiros, na microrregião do litoral paraibano. Das 9 destilarias mencionadas, oito foram implantadas na microrregião do litoral paraibano, próximo da capital do estado. EGLER (1985) aponta que a implantação das destilarias autônomas nos tabuleiros da Paraíba 
preservou, sem disputar, as áreas dominadas pelas usinas, o que não havia ocorrido com os engenhos no passado, com as usinas se sobrepondo àqueles; assim tem-se, hoje, as destilarias lado a lado com as usinas.

Como se pode observar no Quadro 1, no período 1970/80 a área colhida com cana teve um acréscimo de 67.000ha, aumentando em mais de $100 \%$. Na segunda metade dos anos 70, o aumento na área colhida foi superior a $47.000 \mathrm{ha}$, representando um acréscimo de 78,8\%. Em termos absolutos o crescimento do período 1975-80 foi mais de duas vezes o crescimento do quinquênio anterior de pouco mais de 20.000ha. Porém, se em termos percentuais o aumento no período 1975/ $80(78,8 \%)$ foi superior ao do período 1980/85 (66,0\%); verificou-se neste último e em termos absolutos, um aumento da área colhida de quase $71.000 \mathrm{ha}$, superior em quase 24.000 ha ao período $1975 / 80$.

No período 1980-85, observa-se o maior desenvolvimento e auge do programa. O aumento substancial na área colhida foi reflexo do aumento da demanda por cana por parte das destilarias autônomas instaladas no período. A partir de 1985, conforme observamos no Quadro 1 ocorrem declínios na área colhida com cana, que deu sinais de recuperação apenas em 1994/95. Pode-se observar, também, que a produção de cana passa a ter, a partir de 1975 , aumentos sucessivos na quantidade produzida, especialmente nos anos 80 , quando a produção atinge o auge em 1985 e, daí em diante, passa a declinar, recuperando-se em 1994 e 1995. No período 1980/85 tem-se um acréscimo na produção de cana acima dos 5 milhões de toneladas, passando de 5 para 10 milhões de

\section{Quadro 1:}

Evolução do cultivo da cana-de-açúcar no estado da Paraíba, segundo área colhida, quantidade produzida e rendimento médio - 1970/1996

\begin{tabular}{|c|c|c|c|c|c|c|c|}
\hline ANOS & $\begin{array}{c}\text { Área colhida } \\
\text { (ha) }\end{array}$ & $\begin{array}{c}\text { Variação } \\
\text { absoluta (ha) }\end{array}$ & Variação \% & $\begin{array}{c}\text { Quantidade } \\
\text { produzida (t) }\end{array}$ & $\begin{array}{c}\text { Variação } \\
\text { Absoluta (ha) }\end{array}$ & Variação \% & $\begin{array}{c}\text { Rend. Médio } \\
\text { (t/ha) }\end{array}$ \\
\hline 1970 & 40.007 & - & - & 1.433 .245 & - & - & 35,8 \\
\hline 1975 & 60.045 & 20.038 & 50,0 & 2.455 .979 & 1.022 .734 & 71,3 & 40,9 \\
\hline 1980 & 107.376 & 47.331 & 78,8 & 5.213 .040 & 2.757 .061 & 112,2 & 48,5 \\
\hline 1985 & 178.351 & 70.975 & 66,0 & 10.646 .134 & 5.433 .094 & 104,2 & 59,6 \\
\hline 1990 & 156.449 & -21.902 & $-13,9$ & 8.282 .781 & -2.363 .353 & $-28,5$ & 52,9 \\
\hline 1991 & 154.922 & -1.527 & $-0,98$ & 8.115 .401 & -167.380 & $-2,02$ & 52,3 \\
\hline 1992 & 152.454 & -2.468 & $-1,60$ & 7.914 .930 & -200.471 & $-2,47$ & 51,9 \\
\hline $1993^{2}$ & 92.731 & -59.717 & $-39,17$ & 1.837 .607 & -6.077 .323 & $-76,78$ & 19,8 \\
\hline 1994 & 114.390 & 21.659 & 23,35 & 4.586 .335 & 2.748 .728 & 149,58 & 40,0 \\
\hline 1995 & 143.709 & 29319 & 25,63 & 6.775 .755 & 2.189 .420 & 47,73 & 47,1 \\
\hline
\end{tabular}

Fonte: IBGE - Produção Agrícola Municipal, 1970-1995 toneladas de cana, declinando em seguida. Esses incrementos na produção são, antes de tudo, reflexos da expansão dos canaviais em resposta ao aumento da demanda de cana em vez de resultante de incrementos de produtividade.

No que diz respeito ao rendimento agrícola, observou-se que o mesmo acompanhou os incrementos da área e da produção, porém não na mesma magnitude nem no nível em que se esperava; mesmo assim, o nível alcançado em 1985 foi substancial, comparando-se com os níveis anteriores, pois há um crescimento considerável entre 1970 e 1985, auge do Proálcool, passando de 35 para 59 t/ha, porém bem abaixo do nível atingido pelas regiões canavieiras mais importantes de São Paulo, como Bauru, Ribeirão Preto e Campinas, que se situam acima de $80 \mathrm{t} /$ ha. Esse incremento da produtividade em 1985 foi fruto principalmente das pesquisas de novas variedades de cana desenvolvidas, obtendo-se variedades com maior teor de sacarose. Observa-se que a resposta da agricultura canavieira à demanda industrial por cana foi mais significativa em termos extensivos, com o aumento da área plantada, que em termos intensivos, com o aumento do rendimento agrícola, através das inovações técnicas e biológicas na agricultura. Na verdade, observa-se queda no rendimento, situando-se em torno de $50 \mathrm{t} / \mathrm{ha}$ em média a partir da segunda metade dos anos 80 , quando o programa vai perdendo

- 2 O brusco declínio da atividade canavieira no estado, no ano de 1993, deveu-se à grande seca

- pela qual passou a região Nordeste experimentando, conforme se vê no quadro acima, declí-

- nio na área colhida, produção e produtividade do setor. 
força, e reduzindo-se mais ainda nos anos 90 quando se situa abaixo de $50 \mathrm{t} / \mathrm{ha}$.

A redução na atividade agro-industrial como um todo é reflexo da conjuntura econômica interna adversa nos anos 80 , via políticas de controle do déficit público e de controle dos preços do açúcar e do álcool que associadas ao declínio do Proálcool, levaram ao endividamento e à crise econômico-financeira do setor na Paraíba.

No que diz respeito ao segmento industrial do setor, o reflexo do declínio pode ser evidenciado através do Quadro 2 abaixo que apresenta a evolução das usinas e destilarias em funcionamento no estado da Paraíba, no período entre as safras de 1971/72 e 1996/97. A evolução das unidades industriais na Paraíba segue paralela à evolução do Proálcool. Da criação do programa, em 1975, ao auge do programa em 1985/86, foram criadas 8 unidades industriais, todas elas destilarias autônomas acrescendo-se de mais uma na safra de 1988/89 totalizando 16 unidades industriais. Porém, a partir da safra 1993/94, como reflexo da conjuntura econômica e do declínio do programa, o número total de usinas e destilarias em funcionamento cai para 9. Observa-se que a agroindústria na Paraíba, tem-se direcionado para a produção de álcool, uma vez que até a safra 1989/90 o número de usinas manteve-se constante durante todo o período, declinando sucessivamente a partir da safra 1990/91. Por outro lado, cerca de $70 \%$ da cana produzida tem se direcionado para a produção de álcool (ASPLAN, 1995).
Um aspecto importante do ponto de vista da eficiência produtiva do setor sucro-alcooleiro na Paraíba é o de que enquanto as usinas continuavam sob o domínio de grupos familiares, a chamada oligarquia açucareira dominante, as destilari-

Quadro 2:

Evolução das usinas e destilarias anexas e autônomas no ESTADO DA PARAÍBA - 1971/72 A 1996/97

\begin{tabular}{|c|c|c|c|c|}
\hline SAFRAS & USINAS & DESTIL. AUTÔN. & DESTIL. ANEXAS & $\begin{array}{l}\text { TOTAL UNID. } \\
\text { INDUSTRIAIS }^{3}\end{array}$ \\
\hline $1971 / 72$ & 7 & 0 & 4 & 7 \\
\hline $1972 / 73$ & 7 & 0 & 3 & 7 \\
\hline $1973 / 74$ & 7 & 0 & 3 & 7 \\
\hline $1974 / 75$ & 7 & 0 & 3 & 7 \\
\hline $1975 / 76$ & 7 & 0 & 2 & 7 \\
\hline $1976 / 77$ & 7 & 0 & 1 & 7 \\
\hline $1977 / 78$ & 7 & 2 & 2 & 9 \\
\hline $1978 / 79$ & 7 & 3 & 3 & 10 \\
\hline $1979 / 80$ & 7 & 4 & 3 & 11 \\
\hline $1980 / 81$ & 7 & 4 & 3 & 11 \\
\hline $1981 / 82$ & 7 & 4 & 4 & 11 \\
\hline $1982 / 83$ & 7 & 6 & 4 & 13 \\
\hline $1983 / 84$ & 7 & 6 & 4 & 13 \\
\hline $1984 / 85$ & 7 & 7 & 4 & 14 \\
\hline $1985 / 86$ & 7 & 8 & 4 & 15 \\
\hline $1986 / 87$ & 7 & 8 & 5 & 15 \\
\hline $1987 / 88$ & 7 & 8 & 5 & 15 \\
\hline $1988 / 89$ & 7 & 9 & 3 & 16 \\
\hline $1989 / 90$ & 7 & 9 & 5 & 16 \\
\hline $1990 / 91$ & 6 & 9 & 5 & 15 \\
\hline $1991 / 92$ & 6 & 9 & 5 & 15 \\
\hline $1992 / 93$ & 6 & 9 & 4 & 15 \\
\hline $1993 / 94$ & 4 & 5 & 1 & 9 \\
\hline $1994 / 95$ & 3 & 6 & 1 & 9 \\
\hline $1995 / 96$ & 3 & 7 & 1 & 10 \\
\hline $1996 / 97^{4}$ & 3 & 7 & 2 & 10 \\
\hline
\end{tabular}

Fonte: ARAGÃO e PAKMAN, 1993, pesquisa direta, 1996

- ${ }^{3}$ Somatório do total de usinas com destilarias anexas mais as destilarias autônomas para cada - safra considerada.

- ${ }^{4}$ A ASPLAN não considerou, na safra 1996/97, a usina Tanques, pois a mesma operou apenas - 2 meses, moendo a cana própria restante. 
as surgiram em sua maioria, sob o domínio de grupos empresariais de Pernambuco. O declínio das usinas e a concentração em alguns poucos grupos faz parte de um mesmo processo, associado à perda de controle dos grupos familiares e, em contrapartida, tem-se a predominância crescente de grupos empresariais no setor que centralizaram a atividade. Entretanto, embora a atividade canavieira passasse das mãos de uma oligarquia tradicional para as mãos de grupos econômicos capitalizados que introduziram técnicas modernas de gestão e continuaram o processo de modernização tecnológica do setor, a concentração da terra continuou e o latifúndio assumiu um novo caráter de dominação.

Pode-se observar ainda, no Quadro 3, que as usinas e destilarias em funcionamento estão, na sua maioria, localizadas no litoral paraibano principalmente nos tabuleiros costeiros, áreas de expansão mais recente dos canaviais. Portanto, a redução da área canavieira, predominantemente na microrregião do Brejo Paraibano, tem acompanhado o fechamento das usinas enquanto as destilarias em funcionamento têm se concentrado na microrregião do litoral paraibano. Até os anos 70, o controle do setor canavieiro-sucroaçucareiro estava nas mãos da família Ribeiro Coutinho. Nos anos 80 e 90, conforme se pode ver nos quadros 3 e 4 , das agroindústrias fechadas a maioria era controlada pela família Ribeiro Coutinho, inclusive a Usina Santana, que estava pa-
O Quadro 5 mostra o desenvol- ralisada e foi arrendada em 1996, e a Usina São João, que continua em dificuldades financeiras. Esta mudança demonstra que, na Paraíba, o setor passou, e continua passando, das mãos de grupos familiares para as mãos de grupos empresariais que utilizam técnicas de gestão mais modernas. vimento e o auge do setor na Paraíba, através da evolução da produção de açúcar e álcool, no período entre as safras de 1975/76 e 1985/86, e o declínio do setor ocorrido após a safra de 1985/86. Analisando-se os dados com respeito à produção de açúcar e álcool a nível estadual observa-se, para o período entre as
Quadro 3:

Usinas e Destilarias em funcionamento no estado da Paraíba, por tipo de unidade, localização e microrregião e grupo econômico que controla - 1996-97

\begin{tabular}{|c|c|c|c|c|}
\hline \multicolumn{5}{|c|}{ Empresas em funcionamento } \\
\hline Usina/Destilaria & Município & Microrregião & Antigo Grupo & Grupo Atual \\
\hline \multicolumn{5}{|l|}{ Usinas } \\
\hline 1. Monte Alegre & Mamanguape & Litoral norte & Familia Fernandes & G. Soares de Oliveira/PB \\
\hline 2. Agroval ${ }^{5}$ & Santa Rita & Litoral central & Familia R. Coutinho & G. Cavalc. de Morais/PE \\
\hline 3. São João & Santa Rita & Litoral central & Família R. Coutinho & Familia R. Coutinho/PB \\
\hline 4. Tanques & Alagoa Grande & Brejo & Família V. Borges/PB & Família V. Borges/PB \\
\hline \multicolumn{5}{|c|}{ Dest. Autônomas } \\
\hline 4. Giasa & Pedras de Fogo & Litoral sul & G. Tavares de Melo/PE & G. Tavares de Melo/PE \\
\hline 5. Pemel & Camaratuba & Litoral norte & G. Pessoa de Melo/PE & G. Pessoa de Melo/PE \\
\hline 6. Tabú & Caaporã & Litoral sul & Grupo Ludgren/PE & G. Ludgren/PE \\
\hline 7. Miriri & Santa Rita & Agro-pastoril & G. Cavalc. de Morais/PE & G. Cavalc. de Morais/PE \\
\hline 8. Jacuípe & Santa Rita & Litoral central & Grupo Agrofertil & G. Cavalc. de Morais/PE \\
\hline 9. Japungú & Santa Rita & Litoral central & G. Cavalc. de Morais/PE & G. Cavalc. de Morais/PE \\
\hline 10.Una & Sapé & Agro-pastoril & Família R. Coutinho & G. Pessoa de Queiroz/PE \\
\hline
\end{tabular}

Fonte: ASPLAN-PB, 1997, ARAGÃO e PAKMAN, 1993, pesquisa direta, 1996/97

Quadro 4:

Usinas e destilarias paralisadas no estado da Paraíba por tipo de unidade, localização (município e microrregião) e grupo econômico que controla - 1996/97

\begin{tabular}{|l|l|l|l|l|}
\hline Empresas Paralisadas \\
\hline Usinas & Município & Microrregião & Antigo Grupo & Grupo Atual \\
\hline 11.Santa Helena & Sapé & Agro pastoril & Família R. Coutinho/PB & Sob intervenção judicial \\
\hline 12.Santa Maria & Areia & Brejo & Família Solon Lins/PB & Sob intervenção judicial \\
\hline 13.Santa Rita & Santa Rita & Litoral central & Familia R. Coutinho/PB & Desativada \\
\hline De $\boldsymbol{s}$ t. A u tô n o m a s & Mamanguape & Litoral norte & F. Valdir dos S. Lima/PB & G. ENARQ/PB \\
\hline 16.Xuá & Brejo & Família R. Coutinho/PB & Sob intervenção judicial \\
\hline 17.Borborema & Pirpirituba
\end{tabular}

Fonte: ASPLAN-PB, 1997, ARAGÃO e PAKMAN, 1993, pesquisa direta, 1996/97

- ${ }^{5}$ A Usina Santana foi arrendada na safra 1996/97, pelo Grupo Cavalcanti de Morais. 
safras 1975/76 e 1985/86, que a produção de açúcar dobrou e a produção de álcool teve um enorme salto, tendo seu maior volume sido atingido na safra 1985/86. A produção de álcool no período 1975/76 era praticamente inexistente, sem significado econômico. A produção de álcool desde o auge do Proálcool tem caído, conforme mostram os dados do período entre as safras 1985/86 e 1996/97.

Para o período em análise, a queda na produção açucareira ocorre paralelamente à redução do número de usinas em operação e ao decréscimo da produção por unidade industrial, o que tem afetado ainda mais os níveis de produtividade industrial. Algumas usinas no estado da Paraíba, no período 1975/76 e 1985/86, chegaram a dobrar a produção de açúcar, enquanto outras a triplicaram, com exceção da Usina São João, que teve decréscimo no período. No período entre as safras
1985/86 e 1990/91, fase de declínio do Proálcool, houve considerável decréscimo na produção em 4 usinas, especialmente na Santa Rita, tendo apenas duas obtido acréscimo. $\mathrm{Na}$ safra 1996/97 fica evidente a estagnação do setor com apenas 3 usinas em funcionamento e dessas, duas tiveram queda expressiva de produção. $\mathrm{O}$ destaque nessa última safra é para a Usina Monte Alegre que, de todo o período analisado, obteve o maior volume de produção.

A produção de álcool no estado da Paraíba (Quadro 6) ganha importância a partir do Proálcool, quando a produção cresce de inexpressivos $533 \mathrm{~m}^{3}$ de álcool em 1975/76 para $308.155 \mathrm{~m}^{3}$ em $1985 / 86$, caindo nas safras seguintes. Comparando-se a safra 1985/86 com a safra 1990/91 verificamos que das 8 destilarias autônomas em funcionamento 5 tiveram decréscimo e três tiveram aumentos de produção com a Japungú tendo um crescimento expressi-

Quadro 5:

Produção de açúcar no estado da Paraíba - safras 1975/76 a 1996/97

\begin{tabular}{|c|c|c|c|c|c|}
\hline Safras & $1975 / 76$ & 1980/81 & 1985/86 & 1990/91 & $1996 / 97^{6}$ \\
\hline Usinas/Destilarias & $\begin{array}{c}\text { Açúcar } \\
\text { sac. } 60 \mathrm{~kg}\end{array}$ & $\begin{array}{c}\text { Açúcar } \\
\text { sac. } 50 \mathrm{~kg}\end{array}$ & $\begin{array}{c}\text { Açúcar } \\
\text { sac. } 50 \mathrm{~kg}\end{array}$ & $\begin{array}{c}\text { Açúcar } \\
\text { sac. } 50 \mathrm{~kg}\end{array}$ & $\begin{array}{l}\text { Açúcar } \\
\text { sac. } 50 \mathrm{~kg}\end{array}$ \\
\hline M. Alegre & 130.682 & 260.910 & 395.750 & 345.000 & 509.546 \\
\hline S. Helena & 382.095 & 500,296 & 680.019 & - & - \\
\hline S. Maria & 184.870 & 535.290 & 434.630 & 325.000 & - \\
\hline S. Rita & 119.145 & 200.702 & 211.308 & 41.000 & - \\
\hline Santana & 148.682 & 353.305 & 559.100 & 583.000 & 324.723 \\
\hline S. João & 428.300 & 511.388 & 420.980 & 513.000 & 343.261 \\
\hline Tanques & 176.466 & 270.493 & 370.589 & 288.000 & - \\
\hline Paraíba & 1.570 .240 & 2.632.384 & 3.072 .376 & 2.095 .000 & 1.177 .530 \\
\hline
\end{tabular}

Fonte: ASPLAN, Relatórios de Produção, vários anos

vo $(56,8 \%)$. Quando comparamos a mudança na produção entre a safra 1985/86 e 1996/97, verificamos que das destilarias autônomas ainda em funcionamento apenas as destilarias Giasa e Japungu tiveram crescimento na produção de $1,6 \%$ e 49,7\% respectivamente, com quedas bruscas nas demais. Associa-se esta queda na produção de álcool à diminuição da oferta de cana por parte dos fornecedores, com os deslocamentos do fornecimento de cana entre destilarias, proporcionado pelo tratamento diferenciado dispensado por algumas usinas e destilarias aos seus fornecedores, tais como fornecimento de adubo, fertilizantes e herbicidas, corte da cana e transporte próprio até a unidade industrial que diminuem as necessidades de capital de giro dos fornecedores. A quebra de muitos fornecedores e de usinas tem resultado na centralização da produção e na concentração fundiária da área canavieira, por parte dos grupos mais fortes do setor.

Quanto ao rendimento industrial (Quadro 7) na produção do açúcar, observa-se crescimento na Usina Monte Alegre nos períodos abaixo considerados, havendo queda de rendimento da Usina São João para o mesmo período, permanecendo estável entre os períodos 1985/86 e 1990/91. Para o álcool em geral, houve melhora no rendimento do setor, como um todo, para o período considerado.

- ${ }^{6} \mathrm{Na}$ safra 1996/97, o levantamento dos dados foi feito até 31/12/96, quando as usinas ainda não

- haviam encerrado as atividades de moagem, que podem se estender até o mês de março. 
Quadro 6:

Produção de álcool no estado da Paraíba - safras 1975/76 a 1996/97

\begin{tabular}{|l|c|c|c|c|c|}
\hline \multicolumn{1}{|c|}{ Safras } & $1975 / 76$ & $1980 / 81$ & $1985 / 86$ & $1990 / 91$ & $1996 / 97^{7}$ \\
\hline \multicolumn{1}{|c|}{ Usinas/Destilarias } & Álcool $\left(\mathbf{m}^{3}\right)$ & Álcool $\left(\mathbf{m}^{3}\right)$ & Álcool $\left(\mathbf{m}^{3}\right)$ & Álcool $\left(\mathbf{m}^{3}\right)$ & Álcool $\left(\mathbf{m}^{3}\right)$ \\
\hline U. S. Helena & 512 & 6.772 & 12.311 & - & - \\
\hline U. S. Maria & - & 2.643 & 10.799 & 1.820 & - \\
\hline U. S. Rita & 21 & - & - & 3.550 & - \\
\hline U. Santana & - & 156 & 9.493 & 11.591 & - \\
\hline U. S. João & - & - & 19.952 & 10.740 & 11.775 \\
\hline D. Giasa & - & 16.568 & 45.285 & 38.159 & 46.042 \\
\hline D. Borborema & - & - & 2.423 & 2.153 & - \\
\hline D. Jacuípe & - & - & 19.381 & 19.454 & 14.416 \\
\hline D. Japungu & - & 17.620 & 43.535 & 37.182 & 27.065 \\
\hline D. Miriri & - & 21.305 & 60.030 & 35.686 & 23.369 \\
\hline D. Pemel & - & - & 16.676 & 7.241 & - \\
\hline D. Tabu & 533 & 74.335 & 308.155 & 264.552 & 186.285 \\
\hline D. Una & & - & 40.250 & 46.200 & 21.677 \\
\hline Paraiba & & & & &
\end{tabular}

Fonte: ASPLAN, Relatórios de Produção, vários anos

Quadro 7:

Rendimento industrial das usinas e destilarias no estado da Paraíba

\begin{tabular}{|l|c|c|c|c|c|c|}
\hline \multicolumn{1}{|c|}{ Safras } & \multicolumn{2}{c|}{$1985 / 86$} & \multicolumn{2}{c|}{$1990 / 91$} & \multicolumn{2}{c|}{$1995 / 96$} \\
\hline Unid. Industriais & açúcar & álcool & açúcar & álcool & açúcar & álcool \\
\hline Monte Alegre & 79,5 & & 80,6 & & 94,0 & \\
\hline Santana & 86,5 & & 81,5 & & & \\
\hline São João & 89,9 & & 84,6 & & 73,3 & \\
\hline Giasa & & 100,0 & & 75,3 & & 85,1 \\
\hline Japungú & & 76,2 & & 74,9 & & 82,3 \\
\hline Jacuípe & & 74,0 & & 86,0 & & 79,1 \\
\hline Miriri & & 74,0 & & 73,0 & & 82,3 \\
\hline Una & & 64,5 & & 82,4 & & 100,0 \\
\hline
\end{tabular}

Fonte: ASPLAN, relatórios de produção, vários anos

\section{Procedimentos metodológicos}

Foram feitos estudos de caso em 8 unidades industriais, sendo 5 destilarias autônomas e 3 usinas, com 2 delas contando com destilaria ane$\mathrm{xa}$, todas concentradas na microrre- gião do Litoral Paraibano. Foram aplicados questionários e feitas entrevistas com os gerentes industriais e agrícolas e as unidades industriais visitadas foram: as Usinas Santana e São João (ambas com destilaria anexa) no município de Santa Rita; a Usina Monte Alegre, no município de Mamanguape; as destilarias Japungú, Jacuípe e Miriri, em Santa Rita; a destilaria Arthur Tavares (GIASA) no município de Pedras de Fogo, e a destilaria Una, no município de Sapé.

Dividiu-se o questionário em 4 partes, conforme o objeto de investigação do estudo, em que a primeira trata dos financiamentos para o setor, a segunda das inovações tecnológicas e modernização em nível industrial, a terceira cuida da comercialização dos produtos do setor e a quarta parte trata das inovações tecnológicas e da modernização, a nível do setor agrícola, e dos sistemas de produção utilizados nas tarefas do ciclo da atividade canavieira.

É importante que se mencione que a determinação do grau de modernização das unidades industriais visitadas foi baseada na percepção dos gerentes industriais e agrícolas quanto ao perfil tecnológico existente comparado ao perfil tecnológico das empresas concorrentes e ao padrão tecnológico atualmente existente no mercado, em vez de se verificar se realmente o padrão tecnológico existente nas unidades industriais paraibana correspondem ou não aos padrões mais modernos das tecnologias existentes no mercado, o que seria um procedimento mais objetivo, mas que exigiria um trabalho muito mais exaustivo. Para determinar o grau de modernização pedem-se para os gerentes classificarem como a sua empresa se situ- 
ava em relação aos concorrentes paraibanos, assim como em relação às tecnologias mais modernas existentes: se estavam na média, abaixo da média ou acima da média.

\section{Perfil das usinas e destilarias}

\section{Investimentos e financiamento das usinas}

As usinas atualmente em funcionamento na Paraíba datam sua fundação do final do século passado e primeira metade deste século e no geral possuem um parque industrial sucateado, não tendo sido realizado modernizações significativas. Tem-se, ao contrário, o seu declínio, resultando no fechamento, arrendamento ou venda, quase sempre aos grupos que atuam na produção de álcool, como tem ocorrido atualmente com a usina Santana, no município de Santa Rita, resultando, como já mencionamos, na centralização da produção do setor. Os investimentos praticamente estagnaram, não havendo uma contínua modernização dos equipamentos e instalações na indústria, porém algumas delas foram ampliadas na época do Proálcool, implantando destilarias anexas.

As usinas Santa Helena, Santa Rita e Santa Maria estão desativadas desde o início da década. Um caso à parte é a usina Monte Alegre, sob o controle do grupo Soares de Oliveira, de origem paraibana, que atua em outros setores da economia. Apesar das dificuldades enfrentadas, a usina Monte Alegre tem consegui- do manter um razoável ritmo de investimentos, tanto no setor agrícola como no industrial, desde que o Grupo Soares de Oliveira assumiu o controle e tem mantido elevado o volume de produção de açúcar, que tanto é exportado como comercializado no mercado regional. O grupo tem investido ultimamente na comercialização do açúcar a varejo para o mercado local criando sua própria marca.

Observou-se que a sobrevivência das usinas esteve ligada à regulação estatal do setor, através dos financiamentos e subsídios administrados pelo IAA e quando estes escassearam ou acabaram, as usinas entraram em crise financeira e declínio, chegando quase todas a fechar. $\mathrm{O}$ volume de produção das usinas é baixo, atendendo principalmente ao mercado local. A história das usinas na Paraíba está diretamente associada ao domínio das tradicionais famílias no controle das mesmas, formadas pela oligarquia açucareira.

As condições econômico-financeiras das usinas desde final dos anos 80 e por toda essa década, não têm permitido se auto-sustentar quando o apoio estatal escasseou, mesmo algumas daquelas que diversificaram a produção, produzindo também álcool. O quadro presente para o setor sucro-alcooleiro, com o corte nos financiamentos e no volume de subsídios, requer a realização de investimentos com recursos próprios, o que tem sido possível apenas para algumas destilarias. Pôde-se constatar que boa parte das empresas, especialmente as destilarias, conseguiu se auto-sustentar e desen- volver-se, mesmo face à conjuntura econômica desfavorável dos anos 80 e a crise posterior do Proálcool.

\section{Modernização tecnológica das usi- nas}

No que diz respeito ao grau de modernização tecnológica, a Monte Alegre está numa posição acima da média em relação às outras usinas, desde que foi adquirida pelo Grupo Soares de Oliveira. A empresa tem implantado sistemas de automação no processo de centrifugação do açúcar, mesa alimentadora de cana e geradores, para obtenção de energia própria. A usina Agroval (exSantana) encontra-se na média entre as empresas do setor, porém vale destacar que o Grupo Cavalcante de Morais, desde que a adquiriu, tem feito importantes investimentos tecnológicos na empresa, como na automação das turbinas de açúcar. A usina São João, pertencente à família Ribeiro Coutinho, não tem feito investimentos na empresa, estando esta defasada tecnologicamente, com o parque industrial sucateado, tratando-se da mais antiga usina do estado, cuja fundação data de 1888 .

As usinas produzem dois tipos de açúcar: o cristal e o demerara, tendo a produção de álcool, naquelas usinas com destilaria anexa, se reduzido bastante. $\mathrm{O}$ açúcar refinado, que passa por um processamento industrial mais consistente, é comercializado internamente no varejo e atacado, enquanto o açúcar demerara é totalmente exportado "in natura” para a Europa e para o mercado preferencial 
dos Estados Unidos, sendo reprocessado industrialmente e comercializado para o mundo sob nova fórmula, do tipo diet, para um mercado atualmente em expansão, do qual o Brasil representa um dos grande mercados potenciais ${ }^{8}$.

As usinas são tradicionalmente proprietárias de grandes extensões de terras nas microrregiões do Litoral e Brejo Paraibano, onde se concentra hoje a quase totalidade da cultura canavieira. O período de instalação das destilarias coincide com a apropriação de terras de posseiros por parte das destilariasde na faixa dos tabuleiros litorâneos. Embora fosse marcante a presença dos fornecedores no abastecimento de cana das usinas até o início dos anos 70, a partir do Proálcool as usinas procuram aumentar a produção de cana própria como estratégia para garantir um suprimento regular e diminuir o risco de fornecimento.

\section{A modernização das destilarias}

As destilarias autônomas vêm passando por um processo de centralização de capital sob o controle de grupos empresariais de Pernambuco, a exemplo do Grupo Cavalcante de Morais que controla 1 usina e 3 destilarias. Algumas destilarias apresentam um padrão de modernização industrial comparável às melhores destilarias do país, já que os equipamentos e instalações da mai- oria das destilarias foram adquiridos recentemente e novos equipamentos de ponta foram posteriormente adicionados, permitindo menores custos, melhor consistência e qualidade do produto e maior eficiência da empresa, além de diversificar a produção. $\mathrm{O}$ maior referencial do padrão de modernização tem sido os investimentos em automação e informatização dos sistemas de controle dos sub-setores que perfazem o ciclo de produção do álcool. Em sua maioria, as destilarias autônomas na Paraíba têm modernizado nos sub-setores de produção e nos processos de produção no setor agrícola e industrial, como é o caso das destilarias Japungú, Miriri e Giasa.

As destilarias têm diversificado suas atividades produzindo, além do álcool automotivo, álcool especial (neutro) para fins industriais, especificamente para as indústrias de bebida, cosmética, farmacêutica e perfumaria, sendo em maior volume exportado para a Rússia, França, Japão e EUA. A destilaria Giasa, em particular, faz operações de drawback, importando álcool da Índia e reprocessando-o, produzindo o álcool neutro, exportado para os países acima mencionados. $\mathrm{O}$ álcool anidro e o hidratado são comercializados quase que totalmente no mercado interno regional.
As destilaria anexas e as autônomas na Paraíba foram implantadas com recursos do Proálcool que perduraram do início do programa até o final da sua fase áurea na safra 1986/87. Os recursos do programa se destinaram a investimento na implantação das empresas, na aquisição de equipamentos e no custeio e comercialização dos produtos do setor. A título de ilustração, a destilaria Giasa possui sistema de automação no setor de moagem da cana, das caldeiras e do laboratório do Pagamento da Cana pelo Teor de Sacarose (PCTS) e informatização com Controlador Lógico Programável (CLP) das plantas industriais para fabricação do álcool neutro.

Pode-se observar o contraste entre o arcaico e o moderno numa mesma empresa, uma vez que foram instaladas destilarias modernas anexas às usinas tradicionais existentes. Enquanto o equipamento das usinas é velho e sucateado, o parque industrial alcooleiro tem pouco mais de 20 anos de existência e as empresas continuam a modernizar os equipamentos e instalações. Quanto ao grau de modernização tecnológica das destilarias autônomas, a Japungu, a Jacuípe, a Miriri e a Giasa são as mais modernas do estado e têm nível tecnológico similar, enquanto a destilaria Una se encontra tecnologicamente abaixo destas empresas.

- ${ }^{8}$ Um exemplo destes novos produtos diet derivados do açúcar é a substância sucralose, um

- adoçante dietético, produzido e comercializado com o nome de Splenda pela Johnson \& John-

- son. 


\section{Modernização agrícola}

Nas destilarias, a maior parte do fornecimento da cana provém de terras próprias e de acionistas das empresas, enquanto o restante da cana fornecida provém quase que totalmente de grandes fornecedores. Por se localizarem nos tabuleiros costeiros, compostos de solos de baixa fertilidade, as destilarias constantemente fazem análise do solo, usando como correção métodos de conservação, como curva de nível, aração e gradagem em contorno, terraços e sistema de rotação. Com exceção da Una, localizada no município de Sapé, onde as terras são mais férteis, todas as terras de produção de cana das destilarias, localizadas nos tabuleiros costeiros, sofrem o problema de erosão do solo, sendo necessário se fazer, constantemente, correções do solo. Algumas fazem uso da adubação verde das folhas dos canaviais, como forma de preservação da fertilidade do solo.

O preparo do solo é feito através da aração e gradagem motomecanizada e com a grade aradora, como métodos mais utilizados por todas as usinas e destilarias, representando o mais avançado para a região. Nesta fase de preparo do solo prevalece o sistema tradicional. Todas as empresas fazem adubação e a maior utilização de adubos é feita pelas destilarias, visto que todas elas utilizam o adubo químico, especialmente fertilizantes; depois vêm os adubos naturais, através da adubação verde e da utilização do vinhoto, que vem sendo utilizado mais recentemente, apresentando produtividade satisfatória e resultando no aumento do teor de sacarose da cana. A adubação verde ocorre em pequenas áreas, prevalecendo a prática das queimadas.

Para o combate de pragas nos canaviais são utilizados herbicidas, pesticidas e formicidas, que têm maior utilização por parte das destilarias. Os equipamentos utilizados para combate às pragas são, predominantemente, o costal manual e o costal motorizado, com algumas destilarias mais modernas utilizando tratores e, em alguns casos, avião, a exemplo das destilarias Giasa, Japungu e da Usina Agroval.

As empresas utilizam métodos de plantio manual e mecânico, este último do tipo motomecanizado, em maior escala. O sistema motomecanizado permite maior produtividade e eficiência nesta tarefa. A técnica de corte e colheita da cana é totalmente manual. A utilização de caminhões e treminhões é predominante no transporte da cana do campo à indústria, reduzindo a perda do teor de sacarose da cana, ao mesmo tempo em que permite maior agilidade no processo de entrega, não causando interrupções no processo.

Quanto ao uso de variedades de cana, foi feito o levantamento de 9 variedades de cana, consideradas as mais indicadas para o manejo nas áreas canavieiras do Nordeste. A orientação das variedades utilizadas parte das próprias empresas; sendo as variedades de cana próprias das empresas e adquiridas através da UFRPE (Universidade Federal Rural de Pernambuco) ou, ainda, através de órgãos de pesquisa. $\mathrm{Na}$ épo- ca do Proálcool, através do Planalsucar, era maior o estímulo às pesquisas e desenvolvimento de novas variedades e sua distribuição para as usinas e destilarias. Porém, com a crise do Proálcool, o Planalsucar foi desativado, a exemplo da Estação Experimental de Camaratuba, no litoral-norte da Paraíba, ficando as pesquisas a cargo de órgãos financiados pelas próprias empresas do setor, tendo em Pernambuco a Estação de Carpina e, em São Paulo, o Coopersucar, como maior órgão de pesquisa para o setor no Brasil e um dos mais avançados do mundo.

O manejo de variedades de cana é a principal meta a ser trabalhada pelas empresas. A utilização adequada do manejo é de grande importância no desenvolvimento tecnológico do setor canavieiro, o que permitirá a obtenção de maiores rendimentos nos setores agrícola e industrial. Afirmam os agrônomos da EECAC, em Pernambuco que, após 10 a 15 anos de cultivo de cana, a maioria das variedades entra em degenerescência ficando, assim, mais suscetíveis a doenças e ataques de pragas. Acrescentam, ainda, que "o uso adequado de variedades é de fundamental importância para o sucesso econômico da agroindústria canavieira". (MANUAL SUCROALCOOLEIRO DO ESTADO DA PARAÍBA, 1997)

As variedades abaixo relacionadas (Quadro 8) foram selecionadas segundo o grau de produtividade, teor de sacarose, período de maturação, teor de fibra, período de utilização industrial e reação às doenças, entre outras qualidades. A CB 
45-3, desenvolvida em meados dos anos 70, é a única utilizada por todas as empresas, com exceção da usina São João. Também da mesma época, a CO 997 é utilizada por quase todas as empresas, com exceção da destilaria Una e da usina São João. O uso dessas variedades predomina nas terras das destilarias por ser quase a totalidade adaptada às condições edafoclimáticas dos tabuleiros costeiros. Algumas variedades já estão em desuso ou praticamente extintas, por terem entrado em processo de degenerescência, devido ao longo tempo de uso.

Do levantamento das variedades de cana utilizadas e de suas qualidades, constatou-se que o grande problema que se coloca para o setor é o adequado manejo das variedades e, mais ainda, a descoberta de novas variedades que congreguem, num único tipo, ótimas condições de produtividade, alto teor de sacarose, adaptadas às condições edafoclimáticas e resistência às pragas e às doenças. Este é o grande desafio da pesquisa. O problema do combate às pragas e doenças da cana é dos mais sintomáticos, visto que as 9 variedades de cana selecionadas apresentam boas condições de produtividade e teor de sacarose. Algumas das variedades mais utilizadas pelas empresas são, em sua maioria, de boa a alto com relação ao teor de sacarose e de boa a alta com relação a produtividade, além de algumas serem excepcionais nessas qualidades mas, em contrapartida, suscetíveis a doenças e/ou pragas e, em certos casos, com grau de degenerescência elevado, entrando em desuso.

As condições de clima quente e seco do Nordeste permitem a infestação das doenças e a propagação das pragas nos canaviais. As cinco doenças de maior potencial na cultura da cana são:

1. raquitismo da soqueira, considerada das mais importantes, torna a cana mais raquítica e fina que as normais;

2. escaldadura das folhas que, em fase aguda, pode levar à perda total do canavial pela queima das

Quadro 8:

Relação das variedades de cana mais produtivas e seu uso pelas usians e destilarias

\begin{tabular}{|l|c|c|c|c|c|c|c|c|}
\hline \multicolumn{1}{|c|}{ Usinas/Destilar. } & $\begin{array}{c}\text { Monte } \\
\text { Alegre }\end{array}$ & São João & Agroval & Japungú & Jacuípe & Giasa & Miriri & Una \\
\hline \multicolumn{1}{|c|}{ Variedades } & & & & & & & & \\
\hline 1) 4B 72454 & $\mathrm{X}$ & & & $\mathrm{X}$ & $\mathrm{X}$ & $\mathrm{X}$ & $\mathrm{X}$ & $\mathrm{X}$ \\
\hline 2) RB 813804 & & & & & & & $\mathrm{X}$ & \\
\hline 3) RB 83102 & & & & & & $\mathrm{X}$ & $\mathrm{X}$ & \\
\hline 4) SP 701143 & $\mathrm{X}$ & & & $\mathrm{X}$ & $\mathrm{X}$ & $\mathrm{X}$ & $\mathrm{X}$ & $\mathrm{X}$ \\
\hline 5) SP 716949 & & & $\mathrm{X}$ & $\mathrm{X}$ & $\mathrm{X}$ & $\mathrm{X}$ & $\mathrm{X}$ & $\mathrm{X}$ \\
\hline 6) SP 784764 & & & & & & & $\mathrm{X}$ & \\
\hline 7) SP 791011 & & & & $\mathrm{X}$ & $\mathrm{X}$ & $\mathrm{X}$ & $\mathrm{X}$ & \\
\hline 8) CB 45-3 & $\mathrm{X}$ & & $\mathrm{X}$ & $\mathrm{X}$ & $\mathrm{X}$ & $\mathrm{X}$ & $\mathrm{X}$ & $\mathrm{X}$ \\
\hline 9) CO 997 & $\mathrm{X}$ & & $\mathrm{X}$ & $\mathrm{X}$ & $\mathrm{X}$ & $\mathrm{X}$ & $\mathrm{X}$ & \\
\hline
\end{tabular}

Fonte: SINDÁLCOOL E ASPLAN, 1997

folhas, como se estivesse sido escaldada; daí o nome e morte dos colmos;

3. podridão da casca, em que o fungo causador é um dos responsáveis pela deterioração da cana durante o corte, transporte e armazenamento, levando à diminuição do rendimento de sacarose;

\section{4. síndrome do mau desenvolvi-} mento, que ocorre nos tabuleiros de solos arenosos e na areia branca de baixa fertilidade associado a uma seca prolongada e a altas temperaturas, levando ao baixo desenvolvimento da cana na época chuvosa e à secagem e morte da cana nos períodos de estiagem;

5. podridão vermelha, cuja ocorrência é generalizada nas regiões canavieiras, especialmente nos períodos de seca prolongada; causando a morte das gemas e reduzindo significativamente a brotação.

Quanto às pragas, destacam-se, com maior freqüência:

1. a cigarrinha da folha, que ocasiona perdas no peso e no teor de sacarose da cana;

2. a broca comum, que leva também à perda de peso e do teor de sacarose;

3. a broca gigante, que tem afetado, com maior freqüência, a $\mathrm{Pa}$ raíba, reduz o poder germinativo causando, também, na cana jovem, a secagem e o posterior 
apodrecimento da "olhadura"; na cana adulta ataca os entrenós mais ricos em sacarose. (MANUAL SUCROALCOOLEIRO DO ESTADO DA PARAIBA, 1997).

\section{Conclusões}

Concluiu-se que a questão da baixa produtividade encontra-se principalmente, no setor agrícola, uma vez que a qualidade das terras é um importante fator limitante do aumento da produtividade. $\mathrm{O}$ descompasso no processo de modernização entre o setor agrícola e o setor industrial foi o fator de entrave à modernização plena do complexo canavieiro-sucro-alcooleiro na Paraíba. O setor na Paraíba enfrenta ainda o problema da falta de atividades de Pesquisa e Desenvolvimento ( $\mathrm{P} \& \mathrm{D})$. Coexistem sistemas modernos e tradicionais de produção na agricultura canavieira.

As usinas apresentam um padrão tecnológico arcaico; tem-se um parque açucareiro sucateado, com baixo nível de capitalização no setor agrícola e industrial. Uma das características estruturais do setor açucareiro é o seu domínio por famílias tradicionais, as oligarquias açucareiras, que sempre estiveram atreladas ao protecionismo estatal e que tinham uma atitude gerencial que resultou em baixo nível de investimentos e modernização do setor. O endividamento, o baixo nível de produtividade e competitividade no mercado nacional, são fatores que respondem pela crise que, atualmente, afeta as usinas na Paraíba. As destilarias, por sua vez, têm continuamente modernizado tecnologicamente e racionalizado o processo produtivo e diversificado a produção tendo até conseguido uma inserção no mercado internacional.

Em síntese, pode-se afirmar que a estagnação, declínio e crise das usinas e algumas destilarias estão associados, em grande parte, ao controle e domínio das mesmas pelas grupos oligárquicos familiares tradicionais que gerenciavam essas indústrias. A crise dessas indústrias reflete os problemas do gerenciamento e controle por esses grupos oligárquicos tradicionais; por outro lado, o sucesso das destilarias está associado ao controle das mesmas por grupos econômicos empresariais.

\section{Referências bibliográficas}

ARAGÃO, Paulo Ortiz Rocha de. A Economia Política do Açúcar e do Álcool no Brasil. Série Debates, $\mathrm{n}^{0}$ 39. Cadernos de Economia (mestrado em Economia), Campina Grande, 1993, 160

ARAGÃO, Paulo Ortiz Rocha de, PAKMAN, Elbio Troccoli. “ $O$ PROÁLCOOL e as Transformações no Espaço Agrícola da Paraíba". Revista Raízes, $\mathrm{n}^{\circ} 8$, janeiro/dezembro 1991. Mestrado em Economia-UFPb, Campina Grande, 1991, 220 p.
ASPLAN. A Realidade do Setor Canavieiro da Paraíba, João Pessoa, 1995.

Relatórios de Produção, vários anos.

BARROS, Alexandre R. "Uma Avaliação das Políticas para o Setor Sucroalcooleiro no Brasil: o Que a Nova Evidência Mostra”. Revista Econômica do Nordeste, vol. 27, $\mathrm{n}^{\mathrm{o}}$ 3, jul./ set. de 1996.

DIÁRIO DE PERNAMBUCO, Recife, PE, 18 de maio de 1997 , arquivo pessoal de recortes.

EGLER, Claúdio Antonio G. "Os impactos do Proálcool na Paraiba”. Geonordeste. Série Impactos Tecnológicos - CODECIT, ano I, 1984.

IBGE. Produção Agrícola Municipal. Paraíba, 1970/95.

LIMA, S.R.R. Modernização e Crise no Setor Sucroalcooleiro da Paraíba, 1970-1997. Dissertação de Mestrado, $\mathrm{UFPb}$, Campina Grande, 1997, 160 p.

MOREIRA, Emília de R. F; Moreira, Ivan T. Agroindústria Canavieira Paraibana: $\boldsymbol{E}_{\boldsymbol{X}}$ pansão e Crise. João Pessoa, PB, 1992.

NOVAES, José Roberto. Modernização, Relações de Trabalho e Poder. Um Estudo das Transformações Recentes na Agroin- 
Sergio Ricardo Ribeiro de Lima e Paulo Ortiz Rocha de Aragão

dústria Canavieira do Nordeste. Tese de Doutorado, UNICAMP, Campinas, 1993.

SALES, Teresa. AGRESTE, AGRESTES: Transformações Recentes na Agricultura Nordestina. Série Cadernos CEBRAP. São Paulo, Paz e Terra, 1982, 196 p.

SINDÁLCOOL. Manual Sucroalcooleiro do Estado da Paraíba, João Pessoa, PB, jan. de 1997.

SZMRECSÁNYI, Tamás. $\boldsymbol{O} \boldsymbol{P l a}$ nejamento da Agroindústria Canavieira do Brasil (19301975). Série Economia \& Planejamento. Campinas, HUCITEC/UNICAMP, 1979. 